\title{
PENGUKURAN KINERJA PELAYANAN PUBLIK DENGAN METODE BALANCE SCORECARD (Studi di Kecamatan Jatinangor Kabupaten Sumedang Provinsi Jawa Barat)
}

\author{
Oleh
}

\author{
Yuniar Arofah \\ Mahasiswa Program Pascasarjana Magister Terapan Ilmu Pemerintahan IPDN
}

yun_arofah@yahoo.com

\begin{abstract}
$T$ The Regional Government of West Java Provincial Government Program made Jatinangor District an urban area and an education area which resulted in an increase in the population in the Jatinangor sub-district. With a population of 111,886 in 2016, easy and efficient service is expected by the community. The strategic location of the Jatinangor sub-district with urban areas and education is very supportive in the implementation of service programs to meet community needs. The increasing demands of the community are what encourage sub-district officials to improve the quality of services to the community. This study focused on Performance Measurement in Jatinangor Subdistrict with the Balance Scorecard Method, which is based on the balance scorecard theory. This study aims to determine the performance of public services, the possibilities that occur in the application of balance scorecard and to determine the concept of the measurement strategy of the performance of public services in the District of Jatinangor.

The research method used in this study is a combination of concurrent models in order to answer the first formulation of how the performance of the Jatinangor sub-district is viewed from four perspectives using the quantitative phase by calculating the Community Satisfaction Index (IKM) and using the questionnaire for each perspective, then to answer the problem statement second and third about what obstacles are faced and whether the measurement concept that is suitable for the Jatinangor sub-district uses the qualitative phase with interviews and observations.

The suggestion of this research is that Jatinangor Subdistrict is able to innovate in improving the quality of public services, it is hoped that this method will be taken into consideration for measuring public service performance, and still need further testing and research on the application of balance scorecard with its implementation in each Subdistrict.
\end{abstract}

Keywords: balance scorecard, public service, District Jatinangor

\section{ABSTRAK}

Drogram Pemerintahan Daerah Provinsi Jawa Barat menjadikan Kecamatan Jatinangor sebagai kawasan perkotaan dan kawasan pendidikan yang mengakibatkan semakin meningkatnya jumlah penduduk di kecamatan Jatinangor. Dengan jumlah penduduk 111.886 pada tahun 2016, pelayanan yang mudah dan efisien sangan diharapkan oleh masyarakat. Letak kecamatan Jatinangor yang strategis dengan kawasan perkotaan dan pendidikan sangat menunjang dalam penerapan program pelayanan dalam memenuhi kebutuhan masyarakat. Tuntutan masyarakat yang semakin meningkat itulah yang mendorong aparatur kecamatan untuk meningkatkan kualitas pelayanan terhadap masyarakat. Penelitian ini difokuskan pada Pengukuran Kinerja 
di Kecamatan Jatinangor dengan Metode Balance Scorecard, yang berdasarkan teori balance scorecard. Penelitian ini bertujuan untuk mengetahui kinerja pelayanan publik, kemungkinankemungkinan yang terjadi dalam penerapan balance scorecard serta untuk mengetahui konsep strategi pengukuran kinerja pelayanan publik di Kecamatan Jatinangor.

Metode penelitian yang digunakan dalam penelitian ini adalah metode kombinasi model concurrent di mana untuk menjawab rumusan pertama tentang bagaimana kinerja kecamatan Jatinangor dilihat dari empat perspektif menggunakan fase kuantitatif dengan perhitungan Indeks Kepuasan Masyarakat (IKM) dan menggunakan kuesioner tiap-tiap perspektif, kemudian untuk menjawab rumusan masalah kedua dan ketiga tentang apa saja kendala yang dihadapi dan apakah konsep pengukuran yang sesuai untuk kecamatan Jatinangor menggunakan fase kualitatif dengan wawancara dan observasi.

Saran dari penelitian ini adalah Kecamatan Jatinangor mampu melakukan inovasi dalam meningkatkan kualitas pelayanan publik, diharapkan metode ini menjadi bahan pertimbangan untuk diterapkan pada pengukuran kinerja pelayanan publik, dan masih perlu uji coba dan penelitian penerapan balance scorecard yang lebih lanjut dengan implementasinya di setiap Kecamatan.

Kata kunci: balance scorecard, pelayanan publik, Kecamatan Jatinangor

\section{PENDAHULUAN}

Drogram Pemerintah Daerah Provinsi Jawa Barat menjadikan Kecamatan Jatinangor sebagai kawasan perkotaan dan kawasan pendidikan yang mengakibatkan semakin meningkatnya jumlah penduduk di kecamatan Jatinangor. Dengan jumlah penduduk sebanyak 111.886 pada tahun 2016, pelayanan yang mudah dan efisien sangat diharapkan oleh masyarakat. Letak Kecamatan Jatinangor yang strategis dengan kawasan perkotaan dan pendidikan sangat menunjang dalam penerapan program pelayanan dalam memenuhi kebutuhan masyarakat.Tuntutan masyarakat yang semakin meningkat itulah yang mendorong aparatur kecamatan untuk meningkatkan kualitas pelayanan terhadap masyarakat.

Bagi sebuah organisasi publik, untuk dapat meningkatkan pelayanan publik yang optimal maka SDM yang ada perlu mendapatkan pembelajaran yang terencana, terprogram yang berkesinambungan. Agar dapat berkembang dengan memberikan kualitas layanan publik yang semakin meningkat dari waktu ke waktu, Kecamatan
Jatinangor tentunya harus dapat mengoptimalkan sumber daya manusia yang ada. Jumlah pegawai kecamatan jatinangor berjumlah Pegawai Kecamatan Jatinangor seluruhnya berjumlah 42 orang perlu diimbangi dengan terus melakukan pembelajaran dan pelatihan seiring dengan tuntutan konsumen yang semakin kritis dan semakin meningkat dari waktu ke waktu.

Tingkat kepuasan pelanggan menjadi salah satu tolok ukur, apakah pelayanan yang diberikan dapat dikatakan baik atau tidak. Tingkat kepuasan pelanggan terhadap pelayanan yang diberikan dapat dilihat dari penggunaan teknologi yang canggih, waktu pelayanan yang efektif dan efisien, dan sarana prasarana yang memadai sehingga pelayanan dapat dilakukan secara maksimal. Oleh karena itu dalam kaitan dengan tingkat kepuasan masyarakat, Menteri Pendayagunaan Aparatur Negara mengamanatkan agar setiap penyelenggara pelayanan secara berkala melakukan survei indeks kepuasan masyarakat. Indeks kepuasan masyarakat adalah data dan informasi tentang tingkat kepuasan masyarakat yang diperoleh dari hasil pengukuran secara kuantitatif (teknik penghitungan IKM) atas pendapat 
masyarakat dalam memperoleh pelayanan dari aparatur penyelenggara pelayanan publik dengan membandingkan antara harapan dan kebutuhannya.

Pelayanan aparat Kecamatan Jatinangor kepada masyarakat sampai sejauh mana capaiannya tentu harus dapat diketahui secara terukur dan transparan karena merupakan outcomes dari kinerja Kecamatan Jatinangor maka akan diukur dengan menggunakan Balance Scorecard.Sejauh ini pelayanan aparat Kecamatan Jatinangor belum menunjang sesuai dengan aspek financial terkait dengan realisasi penggunaan keuangan, aspek pelanggan yang belum mengedepankan kepuasan masyarakat dengan perhitungan IKM (Indeks Kepuasan Masyarakat), aspek proses internal yang dalam internal kecamatannya sendiri masih belum terlalu diperhatikan tentang kenyamanan kinerja pegawainya, aspek inovasi dan pembelajaran yang belum memberikan pelatihan dan peningkatan keahlian pegawai serta pemanfaatan peningkatan dan akses dari teknologi informasi.

Latar belakang penggunaan metode Balance Scorecard sebagai alat bantu karena dianggap cukup lengkap untuk menganalisis seluruh aspek dalam sebuah kinerja organisasi publik. Penggunaan Balance Scorecard dalam rangka mengetahui keberhasilan strategi peningkatan kualitas pelayanan adalah untuk membantu merumuskan inisiatif strategi bagi organisasi. Berdasarkan uraian tersebut, selanjutnya dapat diketahui bahwa pengukuran kinerja peningkatan pelayanan dapat dilakukan dalam upaya perumusan inisiatif strategi pada kecamatan Jatinangor diperlukan adanya ukuran kinerja yang berimbang.

\section{LANDASAN TEORI}

\section{KINERJA}

Kinerja adalah hasil atau tingkat keberhasilan seseorang secara keseluruhan selama periode tertentu dalam melaksanakan tugas dibandingkan dengan berbagai kemungkinan, seperti standar hasil kerja, target atau sasaran atau kriteria yang telah ditentukan terlebih dahulu telah disepakati bersama (Rivai dan Basri, 2005: 50).

Mathis dan Jackson (2006: 65) menyatakan bahwa kinerja pada dasarnya adalah apa yang dilakukan atau tidak dilakukan pegawai. Manajemen kinerja adalah keseluruhan kegiatan yang dilakukan untuk meningkatkan kinerja perusahaan atau organisasi, termasuk kinerja masingmasing individu dan kelompok kerja di perusahaan tersebut.

\section{PEngukuran KinerJa}

Konsep Balanced Scorecard dikembangkan oleh Robert S. Kaplan dan David P. Norton yang berawal dari studi tentang pengukuran kinerja di sektor bisnis pada tahun 1990.Balanced Scorecard terdiri dari dua kata, yaitu (1) kartu skor (scorecard) dan berimbang (balanced). Kartu skor adalah kartu yang digunakan untuk mencatat skor hasil kinerja suatu organisasi atau skor individu. Kartu skor juga dapat digunakan untuk merencanakan skor yang hendak diwujudkan pada masa depan. Melalui kartu skor, skor yang hendak diwujudkan organisasi/ individu pada masa depan dibandingkan dengan hasil kinerja sesungguhnya. Hasil perbandingan ini digunakan untuk melakukan evaluasi atas kinerja organisasi/ individu yang bersangkutan. Kata berimbang dimaksudkan untuk menunjukkan bahwa kinerja organisasi/individu diukur secara berimbang dari dua aspek: keuangan dan non keuangan, jangka pendek dan jangka panjang, internal dan eksternal. Dalam definisi lain balanced scorecard adalah suatu konsep untuk mengukur apakah aktivitasaktivitas operasional suatu perusahaan dalam skala yang lebih kecil sejalan dengan sasaran yang lebih besar dalam hal visi dan strategi. 


\section{Pemerintahan Daerah}

Pemerintah daerah merupakan satu kesatuan yang di dalamnya terdapat banyak komponen-komponen penyelenggara pemerintahan yang saling terkait, yaitu kepala daerah, dewan perwakilan rakyat daerah, sekretariat daerah, sekretariat dewan perwakilan rakyat daerah, dinas daerah, serta perangkat daerah otonom lain yang masing-masing memiliki fungsi tertentu yang saling terkait dan ketergantungan.

\section{PElayanan}

Dalam Undang-Undang Nomor 25 Tahun 2009 tentang Pelayanan Publik, yang dimaksud dengan pelayanan publik adalah:

Kegiatan atau rangkaian kegiatan dalam rangka pemenuhan kebutuhan pelayanan sesuai dengan peraturan perundang-undangan bagi setiap warga negara dan penduduk atas barang, jasa dan/atau pelayanan administratif yang disediakan oleh penyelenggara pelayanan publik.

Adapun kriteria yang berkaitan dengan standar kualitas pelayanan kepada masyarakat, yang dapat dijadikan ukuran baik tidaknya suatu pelayanan yang diberikan aparat pemerintah adalah Keputusan Menteri Pendayagunaan Aparatur Negara Nomor 63 Tahun 2003 tentang Pedoman Umum Penyelenggaraan Pelayanan Publik, di mana kriteria- kriteria yang dimaksud adalah merupakan prinsip pelayanan publik. Prinsip-prinsip pelayanan publik tersebut antara lain:

1. Kesederhanaan;

2. Kejelasan;

3. Unit kerja atau pejabat yang berwenang dan bertanggung jawab;

4. Rincian biaya pelayanan publik dan tata cara pembayaran;

5. Kepastian Waktu;

6. Akurasi

7. Keamanan;
8. Tanggung Jawab;

9. Kelengkapan Sarana Prasarana;

10. Kemudahan Akses;

11. Kedisiplinan, Kesopanan, dan Keramahan;

12. Kenyamanan

\section{METODE PENELITIAN}

Desain penelitian yang peneliti gunakan dalam melakukan penelitian tentang Pengukuran Kinerja Pelayanan Publik di Kecamatan Jatinangor dengan mencari kemungkinan penerapan balance scorecard dalam pengukuran kinerja di kecamatan Jatinangor. Untuk itu peneliti memilih untuk menggunakan metode kombinasi model concurrent dalam penelitian yang akan dilakukan.Di mana untuk menjawab rumusan pertama tentang bagaimana kinerja kecamatan jatinangor dilihat dari empat perspektif menggunakan fase kuantitatif dengan perhitungan Indeks Kepuasan Masyarakat (IKM) dan menggunakan kuesioner tiap-tiap perspektif, kemudian untuk menjawab rumusan masalah kedua dan ketiga tentang apa saja kendala yang dihadapi dan apakah konsep pengukuran yang sesuai untuk kecamatan jatinangor menggunakan fase kualitatif dengan wawancara dan observasi.

Dalam penelitian ini peneliti akan mengumpulkan data dari informan yang berkaitan dengan Pengukuran kinerja kecamatan dengan menggunakan metode Balance Scorecard. Informan meliputi tiga macam yaitu :Informan kunci (key informan), informan biasa dan informan tambahan.Di mana informan dalam penelitian ini adalah:

1. Informan kunci yaitu terdiri dari satu orang Camat, satu orang Sekretaris Camat, satu orang Kasubbag Pelayanan Umum, dan empat orang Pegawai yang bekerja pada bidang pelayanan di Kecamatan Jatinangor. 
2. Informan tambahan yaitu masyarakat yang dapat memberikan informasi walaupun tidak langsung terlibat dalam proses pelayanan yang sedang teliti.

Teknik pengumpulan data dalam penelitian yang digunakan peneliti dalam memperoleh data pada penelitian ini adalah melalui penelitian Lapangan (Field Research). Penelitian lapangan adalah teknik pengumpulan data yang dilakukan dengan cara peneliti terjun langsung ke lapangan tempat di mana penelitian diadakan. Maksud diadakan penelitian lapangan ini adalah untuk mendapatkan data dan fakta yang sebenarnya dan ada kaitannya dengan materi yang akan diteliti. Dengan teknik penelitian lapangan diharapkan ditemukan data atau fakta yang aktual dan akurat, karena peneliti dapat melihat dan mengambil secara langsung data atau fakta yang dibutuhkan tanpa melalui orang lain atau media lain. Penelitian lapangan ini dilakukan dengan cara observasi, wawancara, dokumentasi, dan kuesioner. Lokasi Penelitian dilaksanakan di Kecamatan Jatinangor Kabupaten Sumedang.

\section{HASIL PENELITIAN DAN PEMBAHASAN}

Kinerja Kecamatan Jatinangor dilihat dari perspektif finansial, perspektif pelanggan, perspektif proses internal, perspektif pembelajaran dan pertumbuhan karyawan.

\section{Perspektif FinANSiAL}

Kerangka pengukuran kinerja bertujuan untuk mengetahui pencapaian realisasi, kemajuan dan kendala yang dijumpai dalam rangka pencapaian rencana kegiatan, agar dapat dinilai dan dipelajari untuk bahan perbaikan pelaksanaan program/kegiatan pada masa yang akan datang. Selain itu pengukuran kinerja menganalisis efisiensi antara input dan output baik Rencana maupun Realisasi.

Pengukuran kinerja kegiatan di Kecamatan Jatinangor 2017 di antaranya dapat dilihat dari realisasi kegiatan yang berbasis anggaran sebagaimana dalam tabel di bawah ini, di mana hasil pengukuran sampai dengan disusun adalah pelaksanaan kegiatan sampai dengan Juni 2017.

Dari hasil pengukuran kegiatan dapat terlihat bahwa realisasi keuangan dari DPA Kecamatan Jatinangor sampai Desember 2016 yang terserap dari seluruh anggaran Tahun 2016.

Analisis kinerja adalah tingkat pengukuran kinerja penyelenggaraan Pemerintah yang dirumuskan dalam rencana anggaran belanja langsung dalam kurun waktu satu tahun anggaran. Pengukuran kinerja tersebut dilakukan melalui kriteria program yang dilaksanakan, uraian, kegiatan, indikator kinerja, satuan, rencana tingkat capaian (target).

Analisis kinerja di sini mencakup:

1. Kinerja kegiatan yang merupakan tingkat ketercapaian target (rencana tingkat ketercapaian dari masing-masing kelompok indikator kinerja kegiatan)

2. Tingkat capaian sasaran yang merupakan tingkat pencapaian target (rencana tingkat capaian) dari masing-masing indikator sasaran yang telah ditetapkan sebagaimana telah dituangkan dalam rencana kerja pengukuran tingkat pencapaian sasaran yang didasarkan pada data hasil pengukuran kinerja kegiatan.

Maka dapat disimpulkan bahwa kinerja pelayan publik di Kecamatan Jatinangor dilihat dari perspektif finansial dinyatakan cukup baik.

\section{Perspektif Pelanggan}

Berdasarkan Peraturan Menteri Pendayagunaan Aparatur Negara dan Reformasi Birokrasi unsur-unsur yang dijadikan SKM (Survei Kepuasan Masyarakat) sebagai unsur minimal yang harus ada untuk dasar pengukuran Survei kepuasan masyarakat adalah sebagai berikut (Kepmen PAN Nomor. KEP/16/M.PAN/2/2014): 
1. Persyaratan Pelayanan;

2. Prosedur pelayanan;

3. Waktu Pelayanan;

4. Biaya/Tarif Perlayanan;

5. Produk Spesifikasi Jenis Pelayanan;

6. Kompetensi Pelaksana;

7. Perilaku Pelaksana;

8. Maklumat Pelayanan;

9. Penanganan Pengaduan, Saran dan Masukan.

Setelah menganalisis indikator-indikator kinerja di atas berikut ini analisis survei kepuasan masyarakat atas pelayanan publik di Kecamatan Jatinangor Kabupaten Sumedang tahun 2017. Berdasarkan hasil perhitungan di atas maka diperoleh hasil rata-rata kinerja pelayanan sebagai berikut.

Tabel 1 Penilaian SKM dalam Penyelenggaraan Pelayanan

\begin{tabular}{llccc}
\hline NO & \multicolumn{1}{c}{ UNSUR YANG DITELITI } & $\begin{array}{c}\text { NRR } \\
\text { PER UNSUR }\end{array}$ & $\begin{array}{c}\text { NRR TERTIMBANG } \\
\text { PER UNSUR }\end{array}$ & KETERANGAN \\
\hline 1 & Persyaratan Pelayanan & 339 & 2,80 & $\mathrm{~B}$ \\
2 & Prosedur pelayanan & 363 & 3,00 & $\mathrm{~B}$ \\
3 & Waktu Pelayanan & 362 & 2,99 & $\mathrm{~B}$ \\
4 & Biaya/Tarif Perlayanan & 357 & 2,95 & $\mathrm{~B}$ \\
5 & Produk Spesifikasi Jenis Pelayanan & 368 & 3,04 & $\mathrm{~B}$ \\
6 & Kompetensi Pelaksana & 370 & 3,05 & $\mathrm{~B}$ \\
7 & Perilaku Pelaksana & 331 & 2,73 & $\mathrm{~B}$ \\
8 & Maklumat Pelayanan & 361 & 2,98 & $\mathrm{~B}$ \\
9 & Penanganan Pengaduan, Saran & 365 & 3,01 & $\mathrm{~B}$ \\
\hline
\end{tabular}

Sumber: Hasil Pengolahan Jawaban Pertanyaan Kuesioner

Tabel 1 merupakan gambaran seluruh indikator yang diteliti dalam penelitian ini. Dari kesembilan indikator penelitian tersebut seluruhnya mengatakan dalam kategori baik. Untuk mengetahui nilai indeks pelayanan dihitung sebagai berikut.

$(2,80 \times 0,11)+(3,00 \times 0,11)+(2,99 \times 0,11)+(2,95 \times 0,11)+(3,04 \times 0,11)+(3,05 \times 0,11)+(2,73 \times 0,11)+(2,98$ $\mathrm{x} 0,11)+(3,01 \times 0,11)=2,92$

Berdasarkan perhitungan di atas hasil survei kepuasan masyarakat pada pelayanan publik di Kecamatan Jatinangor dapat disimpulkan sebagai berikut.

Tabel 2 Hasil Survei Kepuasan Masyarakat

\begin{tabular}{cccccc}
\hline $\begin{array}{c}\text { Nilai } \\
\text { Persepsi }\end{array}$ & $\begin{array}{c}\text { Nilai Interval } \\
\text { SKM }\end{array}$ & $\begin{array}{c}\text { Nilai Interval } \\
\text { Konversi SKM }\end{array}$ & $\begin{array}{c}\text { Mutu Pe- } \\
\text { layanan }\end{array}$ & $\begin{array}{c}\text { Kinerja Unit } \\
\text { Pelayanan }\end{array}$ & $\begin{array}{c}\text { Nilai } \\
\text { SKM }\end{array}$ \\
\hline 1 & $1,00-1,75$ & $25-43,75$ & D & Tidak baik & \\
2 & $1,76-2,50$ & $43,76-62,50$ & C & Kurang Baik & $\mathbf{7 3}$ \\
3 & $2,51-3,25$ & $62,51-81,25$ & B & Baik & \\
4 & $3,26-4,00$ & $81,26-100$ & A & Sangat Baik & \\
\hline
\end{tabular}

Sumber: Pengolaan SKM 
Dari tabel 2 di atas dapat disimpulkan bahwa kinerja pelayanan publik di Kecamatan Jatinangor dilihat dari perspektif pelanggan menunjukkan kinerja pelayanan publik berpredikat "BAIK" dengan nilai SKM 73. Secara keseluruhan kinerja pelayanan publik di Kecamatan Jatinangor dikatakan Baik. Persyaratan pelayanan mudah dipenuhi, prosedur pelayanan sesuai dengan standar pelayanan, hasil pelayanan sesuai dengan yang diharapkan, kompetensi petugas yang memadai/terampil dalam pelayanan, perilaku petugas dalam memberikan pelayanan sangat baik, adanya kesanggupan petugas dalam memberikan pelayanan serta penanganan pengaduan yang telah dilengkapi dengan fasilitasnya.

\section{Perspektif Proses InTernal}

Melihat indikator dari perspektif proses internal ini mencakup produktivitas, kualitas, waktu penyerahan dan waktu tunggu dari pelayanan yang diberikan, maka indikator tersebut sudah dapat dilihat dari perspektif pelanggan. Namun dalam pembahasan di sini yang dilakukan oleh peneliti dengan melakukan wawancara terhadap pegawai pemberi pelayanan. Di mana dalam hasil wawancara kepada kelapa sub.administrasi pelayanan menyebutkan bahwa: jika melihat dari indikator-indikator yang disebutkan di atas rasanya sudah bagus, karena dalam setiap pemberian pelayanan apa pun kami selalu mengupayakan hasil yang terbaik dengan proses yang cepat.Dan kami sebagai petugas pemberi pelayanan di sini tidak pernah mengulur waktu atau memperlambat pelayanan, yang kami lakukan sudah sesuai dengan SOP pelayanan.

\section{Perspektif Pembelajaran Dan Pertumbuhan Karyawan}

Berikut kami tampilkan daftar pegawai Kecamatan Jatinangor berdasarkan jenjang pendidikan dan yang telah mengikuti pendidikan dan pelatihan adalah sebagai berikut.

Tabel 3 Data Pegawai Kecamatan Jatinangor Berdasarkan Pendidikan dan Pelatihan yang telah Diikuti

\begin{tabular}{llll}
\hline No & Nama & Pendidikan & Latihan Jabatan \\
\hline 1 & Syarif Effendi Badar, S.Sos, M.Si & S-2 & DIKLATPIM II \\
2 & Dase Suheryana, S.Sos.,MM & S-2 & DIKLATPIM III \\
3 & Titih Ratih Irawati, Bsc & D.III & DIKLATPIM IV \\
4 & Iis Yuliani, SE & S-1 & ADUM \\
5 & Cepi Apiril Iskandar & S-1 & \\
6 & Drs. Yuli Handaka & S-1 & ADUM \\
7 & Agus Sobarna, S.Sos.,MT & S-2 & \\
8 & Nurzaman SR, S.Sos & S-1 & \\
9 & Yuningsih, Bsc & D.III & ADUM \\
10 & Ade Sudrajat, S.Kom & S-1 & \\
11 & Tati Hendayati, BA & D.III & ADUM \\
12 & Winarti, SH & S-1 & \\
13 & Singgih Susilowati & SLTA & \\
14 & Elis Limarni Tampubolon & SLTA & \\
15 & Endang Rohmayudi, S.Pd & S-1 & \\
16 & Muhammad Yudi Wibawa, S.Ip & S-1 & \\
17 & Diana Rahmawati & S-1 & \\
\hline
\end{tabular}


Visioner a Vol. $11 \backslash$ No. $1 \backslash$ April 2019: 1 - 10

\begin{tabular}{lll}
\hline 18 & Awam Dawam & S-1 \\
19 & Yudi Yuhanda & SLTA \\
20 & Ade Budialatif & SLTA \\
21 & Ade Rahmat & SLTA \\
22 & Dadang Sobirin & SLTA \\
23 & Ruyani & SLTA \\
24 & Ade Hadian & SD \\
\hline
\end{tabular}

Sumber: Kantor Kecamatan Jatinangor, 2017

Melihat tabel di atas terdapat 2 (dua) orang berpendidikan S2, 11 (sebelas) orang berpendidikan S1, 3 (tiga) orang berpendidikan D3 dan 7 (tujuh) orang berpendidikan SLTA dan 1 (satu) orang berpendidikan SD. Dengan demikian dapat disimpulkan jika melihat dari jenjang pendidikan yang dimiliki oleh pegawai Kecamatan Jatinangor, Kecamatan Jatinangor memiliki sumber daya manusia yang cukup produktif karena sebagian besar pegawainya sudah pada jenjang pendidikan S1 yang cukup mumpuni dalam menjalankan tugasnya sebagai aparat pemerintah.

Merujuk pada tabel di atas pula dapat disimpulkan pengukuran kinerja pelayan publik di Kecamatan Jatinangor dilihat dari perspektif pembelajaran dan pertumbuhan karyawan dapat dikatakan cukup baik, karena pembelajaran dan pelatihan yang didapat oleh pegawai Kecamatan Jatinangor sudah cukup bagus. Hanya tinggal pada inovasi dalam pemberian pelayanan yang belum terlalu beragam.

\section{Strategi Penerapan Pengukuran KinerJa PElayanan PUblik dI KECAMATAN JATINANGOR DENGAN METODE BALANCE SCORECARD}

Berdasarkan kondisi faktual di Kecamatan Jatinangor Kabupaten Sumedang dan hasil pembuatan skenario, maka strategi pengukuran kinerja pelayanan publik di Kecamatan Jatinangor dengan metode balance scorecard adalah sebagai berikut.
1. Sosialisai kepada seluruh aparatur Kecamatan Jatinangor tentang metode pegukuran kinerja dengan menggunakan balance scorecard dan keuntungan penerapannya;

2. Mendorong partisipasi masyarakat dalam proses pembuatan kebijakan, implementasi kebijakan dan pengawasan;

3. Kontrol pemerintah terhadap LSM agar tidak melakukan penyimpangan dalam mengawal pembangunan di Kecamatan Jatinangor Kabupaten Sumedang;

4. Mendorong partai politik agar melaksanakan tugas dan kewajibannya dengan baik, sehingga kepercayaan masyarakat akan semakin meningkat;

5. Melakukan penataan kelembagaan organisasi dengan berpegang pada prinsip efesiensi dan efektivitas dalam pelayanan publik, sehingga jumlah aparat birokrasi tidak terlalu banyak tetapi juga memiliki kualitas dan kompetensi yang memadai;

6. Pengembangan kualitas aparatur pemerintah Kecamatan melalui pendidikan dan pelatihan, seminar, training guna mendukung penerapan metode balance scorecard dalam pengukuran kinerja pelayanan publik. 


\section{SIMPULAN DAN SARAN}

\section{SIMPULAN}

Dari kajian mengenai potret persepsi aparatur pemerintah Kecamatan, skenario lingkungan sosial politik dan ekonomi Kecamatan Jatinangor dalam rangka penerapan pengukuran kinerja pelayanan publik di Kecamatan Jatinangor dengan metode balance scorecard, dapat dibuat simpulan sebagai berikut.

1. Dari hasil penelitian pengukuran kinerja pelayan publik di Kecamatan Jatinangor dengan menggunakan metode balance scorecard yang mencakup empat perspektif penilaian kinerja didapat simpulan dengan rincian sebagai berikut.

a. Perspektif Finansial, kinerja pelayan publik di Kecamatan Jatinangor dilihat dari perspektif finansial dinyatakan cukup baik dengan melihat pada tabel penyerapan anggaran tahun 2016.

b. Perspektif Pelanggan, kinerja pelayanan publik di Kecamatan Jatinangor dilihat dari perspektif pelanggan menunjukkan kinerja pelayanan publik berpredikat "BAIK" dengan nilai SKM 73 sesuai dengan perhitungan SKM.

c. Perspektif proses internal, kinerja pelayanan publik di Kecamatan Jatinangor dengan perspektif proses internal dapat dikatakan baik.

d. Persperktif perspektif inovasi dan pembelajaran dapat dikatakan cukup baik.

2. Skenario penerapan pengukuran kinerja pelayanan publik di Kecamatan Jatinangor dengan metode balance scorecard cenderung berada pada kondisi optimis di mana skenario ini mengembangkan keadaan ekonomi yang baik, kualitas IPM tinggi dengan pengukuran pelayanan yang bagus seperti balance scorecard dapat meningkatkan perekonomian masyarakat. Walaupun sosial politik dalam trend yang kurang baik, civil society dan demokrasi pada tingkat yang lamban, namun para praktisi yakin beberapa tahun yang akan datang akan segera membaik. Dalam kondisi demikian tentunya pengukuran kinerja pelayanan publik di Kecamatan Jatinangor dengan metode balance csorecard membutuhkan waktu yang lama.

3. Dengan melihat skenario yang ada, maka strategi yang dilakukan adalah:

- Sosialisai kepada seluruh aparatur Kecamatan Jatinangor tentang metode pegukuran kinerja dengan menggunakan balance scorecard dan keuntungan penerapannya;

- Mendorong partisipasi masyarakat; Kontrol pemerintah terhadap LSM;

- Melakukan penataan kelembagaan organisasi; serta

- Mengembangkan kualitas aparatur pemerintah Kecamatan.

\section{SARAN}

1. Melihat masalah-masalah yang ada, maka sebaiknya aparat Kecamatan Jatinangor mampu melakukan inovasi dalam meningkatkan kualitas pelayanan publik kepada masyarakat agar semakin baik melalui penerapan pengukuran kinerja dengan metode balance scorecard.

2. Melihat keunggulan yang ada pada metode pengukuran kinerja balance scorecard, diharapkan metode ini menjadi bahan pertimbangan untuk diterapkan pada pengukuran kinerja pelayanan publik.

3. Strategi penerapan pengukuran kinerja dengan metode balance scorecard masih perlu uji coba dan penelitian lebih lanjut dengan implementasinya di setiap kecamatan. 


\section{DAFTAR PUSTAKA}

Silalahi, Ulber, 2012, Metode PenelitianSosial, Bandung, Refika Aditama

Nazir, 2013, Metode Penelitian, Bogor, Ghalia Indonesia.

Kaplan R.S \& D.p. Norton. 1996. "The BSC: Translating Strategy Into Action. Boston" Harvard Business School Press.

Irawan, 2011, Metode PenelitianSosial, Bandung Remaja Rosdakarya.

Mangkunegara, Anwar Prabu. 2002. Manajemen Sumber Daya Manusia. Remaja Rosdakarya. Bandung

Luthans, F. 2005. Organizational Behavior. New York: McGraw-hill.

Mathis, R.L. \& J.H. Jackson. 2006. Human Resource Management: Manajemen Sumber Daya Manusia. Terjemahan Dian Angelia. Jakarta: Salemba Empat.

Nurlaila, 2010. Manajemen Sumber Daya Manusia I. Penerbit LepKhair.

Amstrong, Mischael, 1999. Manajemen Sumber Daya Manusia. Terjemahan Sofyan dan Haryanto. PT. Elex Media Komputindo. Jakarta.

Nasution. 2008.Metode Research (Penelitian Ilmiah). Jakarta. BumiAksara

Nazir, Moh. 2011. Metode Penelitian. Ghalia Indonesia. Jakarta.

Sinambela, Lijan Poltak. 2010. ReformasiPelayananPublik. Jakarta. BumiAksara.

Dunn, William N. 2003. Pengantar Analisis Kebijakan Publik (terjemahan). Yogyakarta: UGM Press.

Gill Ringland. 2002. Scenario in Public Policy. Chicester: Jhon Wiley \& sons. Ltd.

Kaplan, Robert S, dan David P Norton. 1990. Balance Scorecard: Menerapkan Strategi menjadi Aksi, Penerbit Erlangga, Jakarta.

Lindgren, Mats dan Hans Bandhoid. 2003. Scenario Planning The Link Between Future and Strategy. New York. Palgrave Macmillan.
Schwarts, Petter. 2004. Scenario planning Managing For Future. England: Jhon Wiley \& sons.Ltd.

Widodo, Joko. 2001. Good Governance. Telaah dan Dimensi: Akuntabilitas dan Kontrol Birokrasi. Penerbit: Insan Cendekia. Surabaya

Lewis A. Gunn, 1996. Policy Analysis For The Real World. Oxford University Press.

Creswell, W. John. 2010. Research Design Pendekatan Kualitatif. Kuantitatif dan Mixed. Yogyakarta: Pustaka Pelajar.

\section{Peraturan Perundang-Undangan}

Undang-Undang Nomor 23 Tahun 2014 tentang Pemerintahan Daerah.

Undang-Undang Nomor 25 Tahun 2009 tentang Pelayanan Publik.

Peraturan Pemerintah Republik Indonesia Nomor 19 Tahun 2008 tentang Kecamatan.

Keputusan Menteri Pendayagunaan Aparatur Negara Nomor 63/KEP/M. PAN/7/2003 tentang Pedoman Umum Penyelenggaraan Pelayanan Publik.

Peraturan Bupati Sumedang Nomor 46 Tahun 2010 tentang Pedoman Peningkatan Pelayanan Publik di Lingkungan Pemerintah Kabupaten Sumedang.

Peraturan Bupati Sumedang Nomor 45 Tahun 2010 tentang Standar Prosedur Pelayanan Publik di Kecamatan.

Keputusan Menteri Pendayagunaan Aparatur Negara Nomor 16 Tahun 2014 tentang Indeks Kepuasan Masyarakat.

Kecamatan Jatinangor dalam Angka 2016.

Kompas.com, edisi 16 Juli 2016.

Laporan Akuntabilitas Kinerja Instansi Pemerintah (LAKIP) Kecamatan Jatinangor tahu 2016.

id.wikipedia.org/wiki/Masyarakat_mada 